Manuel Caeiro, Towards An Open Lesson Plan Data Model

\title{
TOWARDS AN OPEN LESSON PLAN DATA MODEL
}

\section{HACIA UNA LECCIÓN OPEN MODELO DE DATOS DE PLAN}

\author{
Manuel Caeiro-Rodríguez¹, Miguel Ángel Mendoza-Moreno² \\ Recibido para publicación: 11 de septiembre 2014- Aceptado para publicación: 17 de Octubre 2014
}

\section{RESUMEN}

Este artículo presenta algunas ideas hacia la definición de un modelo de datos para planes de lecciones abiertas. Los planes de lecciones son un tipo particular de recurso de agregación que se pueden incluir otros tipos de recursos educativos, sobre todo objetos de aprendizaje. Desde este punto de vista, consideramos que en el modelo de datos de especificaciones disponibles en el dominio de aprendizaje, tales como la norma de metadatos de objetos de aprendizaje. Esta propuesta del Plan de Lección Abierta se realiza en el contexto de una aplicación Web 2.X, Edu-AREA, encaminado a apoyar la enseñanza y la innovación docente. Esta aplicación permite a los usuarios gestionar los planes de lecciones abiertas como entidades vivas durante su ciclo de vida: desde su diseño, hasta su documentación con los resultados de aprendizaje y los resultados, pasando por su uso durante la enseñanza / aprendizaje de la actividad. En Educación usuarios ÁREA pueden compartir sus planes de estudio y pueden ser copiados, adaptado y "creado" por otros usuarios. Sobre la base de los principios del movimiento de los recursos educativos abiertos, planes de clases abiertas se proponen como una oportunidad para el intercambio y la colaboración entre los usuarios

Palabras Claves: Recursos Educativos Abiertos, Planes de clases abiertas, modelo de datos, 2.X Web

\footnotetext{
$1 \mathrm{M}$. Caeiro-Rodríguez is with the University of Vigo, E.E. Telecomunicación Pontevedra, 36312 Spain (corresponding author; phone: +34-625018450; e-mail: mcaeiro@det.uvigo.es).

2 M.A. Mendoza-Moreno is with the research group Investigación y Desarrollo en Ingeniería del Software- IDIS at the Universidad del Cauca, Colombia and the Universidad Pedagógica y Tecnológica de Colombia. Facultad de Ingeniería- UPTC, Av. Central del Norte, Tunja, Colombia (phone: +57-8-7442999; e-mail: miguel.mendoza@ uptc.edu.co).
} 
Manuel Caeiro, Towards An Open Lesson Plan Data Model

\section{ABSTRACT}

This paper introduces some ideas towards the definition of a data model for open lesson plans. Lesson plans are a particular kind of aggregation resource that can include other types of educational resources, particularly learning objects. From this point of view, we consider on the data model available specifications in the learning domain, such as the Learning Object Metadata standard. This Open Lesson Plan proposal is performed in the context of a Web 2.X application, Edu-AREA, aimed at supporting teaching and teaching innovation. This application enables users to manage open lesson plans as living entities during their life-cycle: from their design, till their documentation with learning results and outcomes, passing through their use during the teaching/learning activity. In Edu- AREA users can share their lesson plans and they can be copied, adapted and "curated" by other users. Based on the principles of the Open Educational Resources movement, open lesson plans are proposed as an opportunity for sharing and collaboration among users.

\section{Keyboards: Open Educational Resources, Open Lesson Plans, Data Model, Web 2.X}

\section{INTRODUCTION}

During the last years many proposals have been published in order to model in a computational way e- learning resources, particularly learning objects and activities. Some of the more relevant initiatives are LOM [1], SCORM [2] and IMS Learning Design [3]. These specifications have been focused on supporting the reusability and interoperability of learning, mainly in on-line and in blended environments. Nowadays, the adoption of Information and Communication Technologies (ICT) to support education has been spread to other contexts and scenarios, such as face-to-face settings. Many primary and secondary traditional teachers are using ICT applications (e.g. social networks, games, simulations) and devices (e.g. tablets) in their daily practice with students. The introduction of these new technologies has also promoted new pedagogies, which can take full advantage of the new opportunities and affordances.

Moreover, this has launched many initiatives and projects towards the support of teaching innovation. In traditional teaching, a lesson plan organizes what a teacher will do and say during teaching sessions. It is a good example of this is the Open Educational Resources (OER) movement [4] that is intended to facilitate the sharing and reuse of educational resources. Traditional teachers can use these resources to prepare their teaching and educational activities arranging them into appropriate constructs. At this point a main issue is to ensure the computational reusability and interoperability of such constructs. "living" artifact that needs to be prepared before teaching, and that can be evolved during its lifetime. Therefore we consider lesson plans as the key construct in order to support teachers on adopting ICT resources and new pedagogies. In addition, following the principles of the OER movement, we propose to the idea of Open Lesson Plans (OLP) as an open construct, that promotes sharing and collaboration. If the lesson plan is shared with others, it provides an opportunity for colleagues, supervisors and others to discuss. The OLP is also proposed as a construct to allow teachers to monitor the teaching process, gathering evidences of the learning results about its development and facilitating the reflection about them. A good lesson plan does not guarantee the success in teaching, but without a clear plan the chances for success are greatly diminished. Similarly, the sharing 
and reflection around OLP can play a key role to support teaching innovation.

This proposal is performed in the context of a Web 2.X application [5] to promote teaching innovation: Edu-AREA [6]. This application (available at http://www.edu-area.com) involves different functionalities around the operation of OLP. It includes a referatory of educational resources. Descriptions and references to different types of educational resources can be included: contents, applications, devices, contributors (people) and trips (events and places outside the school). It is also a repository of teaching/learning activities providing ideas and guidelines for teachers. Learning activities can include links to the resources in the repository. In addition, it is an authoring tool that enables teachers to create OLP arranging activities and resources and also to document the OLP with evidences and reflections captured during the performance of the teaching and learning activities. Finally, a curation functionality is also offered allowing users to classify and annotate resources, activities and lesson plans into different collections (shareboards, in Edu-AREA terminology).

In this paper we will discuss about the different elementsthat can be included in a OLP. In a certain way an OLP can also be considered as an aggregation construct in which learning objects and activities can be included or referenced. Therefore, we consider the accepted standards and specifications about these elements in our discussion see section II. Another relevant source of information in order to define a data model for OLP can be found in the numerous applications that have been developed to support teaching innovation on ICT and new pedagogies. This are reviewed in section III. Next, we introduce the main elements of the data model for OLP. The paper ends with some conclusions.

\section{SPECIFICATIONS FOR LEARNING OBJECTS AND ACTIVITIES}

El presente tema de investigación se seleccionó con la finalidad de ayudar a los niños, jóvenes y adultos con necesidades educativas especiales. El contar con un sistema experto que mejore la calidad de aprendizaje y el desarrollo intelectual de los estudiantes con capacidades especiales permitirá tener una verdadera enseñanza- aprendizaje y de esta manera se logrará cumplir con la base legal de incluir a estos niños en la educación formal y en la sociedad misma.

In this section we analyze several very relevant specifications in the e-learning domain for the description and specification of educational resources. These specifications are taken into account in our proposal.

\section{A. LOM}

IEEE Learning Object Metadata (LOM) was the first IEEE official standard in the e-learning field approved in June 2002 [1]. It proposes a set of data elements to describe learning resources arranged in 9 categories:

- General. It includes fields such as title, language, description and keywords.

- Lifecycle. About main actions related to the life of the resource: creation, author, editor, etc.

- Meta-metadata. Information about the metatada record.

- Technical. About the format, size, location, etc.

- Educational. Features such as difficulty, type, context, etc.

- Rights. About licenses and cost.

- Relation. Relations with other resources.

- Annotation. Comments and descriptions.

- Classification. Presence of the resource in a certain category of a classification schema.

To be compliant with IEEE LOM it is not required to

support the whole set of metadata elements. Indeed all the elements are optional and it can 
be extended. The only request from the standard is not to introduce new elements to replace some of the existing ones. During the last years, several application profiles of LOM have been proposed. These profiles usually identify a subset of data elements to be used from the whole LOM and also introduce specific vocabularies and classification categories to be used. Similarly, we are also considering a specific LOM application profile.

\section{B. SCORM}

SCORM is an standard proposed by the ADL initiative. It involves several specifications, particularly a LOM application profile, and also a content aggregation data model for Learning Objects. Basically, SCORM indicates how to organize different types of contents into a hierarchical structure. More over, SCORM also enables users to define how such contents have to be delivered to a learner by a software system (e.g. an LMS). In this way, SCORM has play a main role supporting the transfer of elearning courses among systems. Most LMSs and e-learning authoring tools enable users to export and import course packages.

From the Edu-AREA point of view a key issue is how to

integrate contents in OLP. First, we conceive this integration in a broader way, not just about contents, but also considering other kind of resources (applications, devices, contributors and trips). In addition, we distinguish between abstract (e.g. graphic editor) and concrete resources (e.g. Paint, Smartdraw, Phtoshop, Piktochart) in order to promote the adaptation. Second, following the ideas presented in [7] we conceive the organization of learning object into different 'layers' depending on their size, similarly to the SCORM hierarchical structure, but based on activities and considering resources at the lower level.

\section{IMS Learning Design}

In 2003, IMS published the IMS Learning Design (IMS LD) specification. This specification was proposed as an alternative to the SCORM standard introducing the concept of learning design. In contrast to the SCORM focus on contents, IMS LD is focused on activities. This involved a Copernican change: learning can be approached in many different ways, not just reading contents, but also with many other activities that can be performed in the classroom, outside the classroom or in the Web. In this way, IMS LD introduces a computational model to describe the activities in a teaching learning activity and other elements involved: participants, applications, order among activities, conditions, etc. In addition, the specification is intended to enable software applications to automatically enact the activity model.

Despite the appropriateness of the approach the adoption of

IMS LD in practice has been a difficult endeavor. A main issue has been how to support the authoring of models of activities that can be enacted automatically. From the point of view of Edu-AREA we approach OLP focusing on activities, but without requiring the automatic enactment. As OLP are mainly tools for teachers, we are mainly interested on their description for people.

\section{LEARNING DESIGN APPLICATIONS}

Despite the lack of direct success, IMS LD specification has promoted the development of the "learning design" area. During these years many proposals and applications have been launched to search for adequate representations of designs of learning activities and objects trying also to include different pedagogical approaches [7]. There are a range of different candidates for how to represent learning design. A general feature is the introduction of visual and intuitive arrangements to facilitate the design and the understanding of the designs. In addition, the need of automatic enactment has diminished in favor of more simplistic models. Next list shows some of the most relevant proposals we have been aware of: 
- A learning design proposal for MOOCs [8]. Identifies 11 issues arranged in two categories: available resources (Human, Intellectual, Equipment, The Platform); and design decisions (General description of the course, target learners, pedagogical approaches, objectives and competencies pursued, learning contents, assessment activities, complementary technologies). A visual canvas to show the 11 issues in a intuitive way is proposed.

- ILDE developed in the METIS project [9]. They are working towards the development of an environment that integrates several learning design tools.

- Web Collage [10] is an authoring tool that propose the use of visual collaborative learning design patterns, as validated techniques, such as: "Jigsaw", "Pyramid", "Brainstorming", etc. These patterns serve as building blocks to generate learning designs. Assessment design patterns are also available.

- The T2 model [11]. It is based on a table/tree structure that maintain a correspondence. The table is proposed to facilitate human understanding and the tree model to enable machine processing. The table columns are related to activities (what must be done), participants (individuals), groups, roles, and resources (objects). Each row in the table is used to relate an activity, to participants, to groups, to roles, and to resources. The tree model refers to the table rows and includes the branching among activities.

- The 4T's model [12]. Focused on Computed Supported Collaborative Learning (CSCL). Defines a schema with 4 components that designers need to focus: Tasks, Teams, Technology and Time. They propose a kind of tabular description of learning designs based on these concepts.

- The Learning Designer [13] is a community knowledge- building tool to support teachers in creating, modifying, finding, sharing and reusing learning designs. It represents learning designs using formal concepts (e.g. Blooms's taxonomy, a typology of forms of learning, activity types). The basic unit are "teaching -learning- activities" (TLAs). It includes a name, notes, group size, duration, learning outcomes, student feedback, analysis of the learning experience (in terms of acquisition, inquiry, discussion, practice and/or production). These TLAs can be situated in a timeline to indicate is sequencing, sized on the basis of their duration.

- OpenGLM [14]. It is a graphical editor that tries to provide an intuitive graphical representation to edit learning designs and produces outcomes compliant with IMS LD, levels A and B.

- CADMOS [15]. It is a graphical editor also aimed at teachers not experts in learning design to support them on creating and sharing designs. It guides teachers on a first stage about activity description (title, description, type, learning goals, prerequisites, roles, resources). Next stage involves the combination of activities to form an activity script.

- 4SPPICes [16]. Also focused on CSCL and on blended scripts. It organizes the design around 4 factors: Space, Participants, Pedagogical and History. A key idea is to combine formal and informal activities occurring across different spatial locations.

- ScenEdit [17] proposes a visual description of learning scenarios. Each scenario includes a textual description and a picture of the items involved in activities: what? Who? For whom?, tools, resources in, Resources Out, and locations. ScenEdit is based on the Intentions, Strategies and interactional Situations conceptual model (ISiS). This model aims to capture teachers' intentions and strategies to facilitate a better understanding of the learning designs by others, and in this way to encourage sharing and reuse.

In previous years some other proposals in the area of learning design had been developed

(check 
http://edutechwiki.unige.ch/en/Educational_mo deling_languag e): OUNL-EML, CPM, PoEML, LDL, E2ML, MISA-MOT+, LAMS, etc. In addition, data model related to the specifications of courses and e-textbooks are also relevant, such as eLML and ePUB.

\section{KEY IDEAS ABOUT THE OLP DATA MODEL}

Edu-AREA can be considered as a kind of learning design authoring tool devoted to support teachers while creating and managing OLP. Some key goals in Edu-AREA are to empower users on the reuse of resources, activities and OLP and to promote teaching innovation. These goals are approached from the application functionality, including a kind of "clone" operation for any public element and recommendations. In addition, we are also interested in defining an appropriate OLP data model that can contribute to those goals. Next sections introduce the main ideas for the data models of educational resources, educational activities and OLP. It is important to notice that activities can involve (reference) educational resources, and OLP are made up of educational activities.

\section{A. Educational Resources}

In relation to educational resources Edu-AREA offers the functionalities of a referatory. In this way, the data model of educational resources is about metadata. Our proposal at this point is to develop a LOM application profile. We have started this model by using a very reduced set of elements: title, description, picture, keywords and link to the real resource. Metametadata info is gathered automatically by the application. Annotation information is also managed by the system but we plan to extend it in order to support user ratings, tags, etc. As next steps we will try to gather more information about the relations with other resources available in Edu-AREA and about the classification of the resource. For example, the classification of an educational content in accordance to the USA Common Core standards. The management of rights metadata will be also tackled in a future development, focusing specially in Creative Common licenses and allowing users to distinguish between private and public information.

A key idea about resources is that we distinguish between concrete and abstract ones. Therefore, we identify a particular kind of hierarchical relation "is-a-kind-of". We will use these relations in order to provide recommendations and to guide users on searching for alternative resources.

Another important issue about these metadata records is that each real word resource can have several metadata records. Basically, different users could have different metadata records about the same resource. Each metadata record will be exclusively in a single language.

We consider another kind of information related to metadata for educational resources: paradata. This is information about the use of a resource. Table I introduces the information we are managing at this level in the platform. It is referred to the different operations that can be done.

The metadata and paradata models for resources are not directly related to the OLP data model. Nevertheless, we are using the same models in case of OLP and educational activities. There are some differences related to the classification schemes, but the rest of elements are applicable.

\begin{tabular}{|l|l|}
\hline Name & Description \\
\hline SocialNetworks & $\begin{array}{l}\text { Communications of the record to social } \\
\text { networks. }\end{array}$ \\
\hline Boards & $\begin{array}{l}\text { Inclusions of the record in users' } \\
\text { shareboards. }\end{array}$ \\
\hline Views & $\begin{array}{l}\text { User views and selections of the record. } \\
\text { elements. }\end{array}$ \\
\hline Adoptions & Copies with modification of a record. \\
\hline Adaptations & \\
\hline
\end{tabular}


Table 1. Elements related to the paradata data model

- Assessment methods and procedures. Containing information about how the outcomes will be assessed.

The previous list introduces the main elements of our data model for educational activities. Nevertheless, we don't want to restrict ourselves to a unique structure. From our experience we know about different activity models: iTEC, WebQuest, eLML, etc. Our goal is to provide a general and flexible activity data model. Therefore, Edu-AREA allows users to create their own templates for educational activities. We distinguish between "textual blocks" and "resource blocks". Both types include a title. In addition, textual blocks include a list of textual items. Resource blocks include a list of references to resources. Users can define their own activity templates including textual blocks for Pedagogical Information and Guidelines. The other elements can be managed with textual blocks or with resource blocks. Fig. 1 shows a view of an activity in Edu-AREA with different blocks where textual blocks have been used for all the

\section{B. Educational Activities}

Educational Activities represent recommendations and suggestions that can be reused by teachers in order to prepare their OLP. They are conceived as units with a certain pedagogical purpose that can also be focused on supporting the achievement of some learning goals by students. The main part of the activity is a set of guidelines that are provided to the teacher in order to prepare, introduce, develop or assess the activity. In addition, activities can include some references to resources that are needed or suggested to be available during the development of the activity. This description gathers the main ideas around the activity data model.

The activity data model involves the same metadata and paradata elements previously explained. In addition, we consider the same distinction between abstract and concrete is maintained. For example, a general brainstorm activity and a brainstorming focused on a math problem. In addition, we also consider specific elements related to an educational activity:

- Pedagogical information. It is possible to include different issues: goals for the teacher, learning goals, competencies, intentions, etc.

- Participants: teachers, learners, groups of learners, etc.

- They are related to general contributor resources.

- Locations: classroom, home, gymnasium, laboratory, etc.

- Resources. Any of the four types of resources can be involved: content, tools, contributors and trips.

- Guidelines. Different blocks of guidelines are possible: to prepare the activity before the classroom, to introduce the activity to the students, actions to be performed, etc.

- Outcomes. Results that have to be produced as a result of the development of the activity. This will be indicated as references to abstract contents. For example: a video, a picture, a document. 


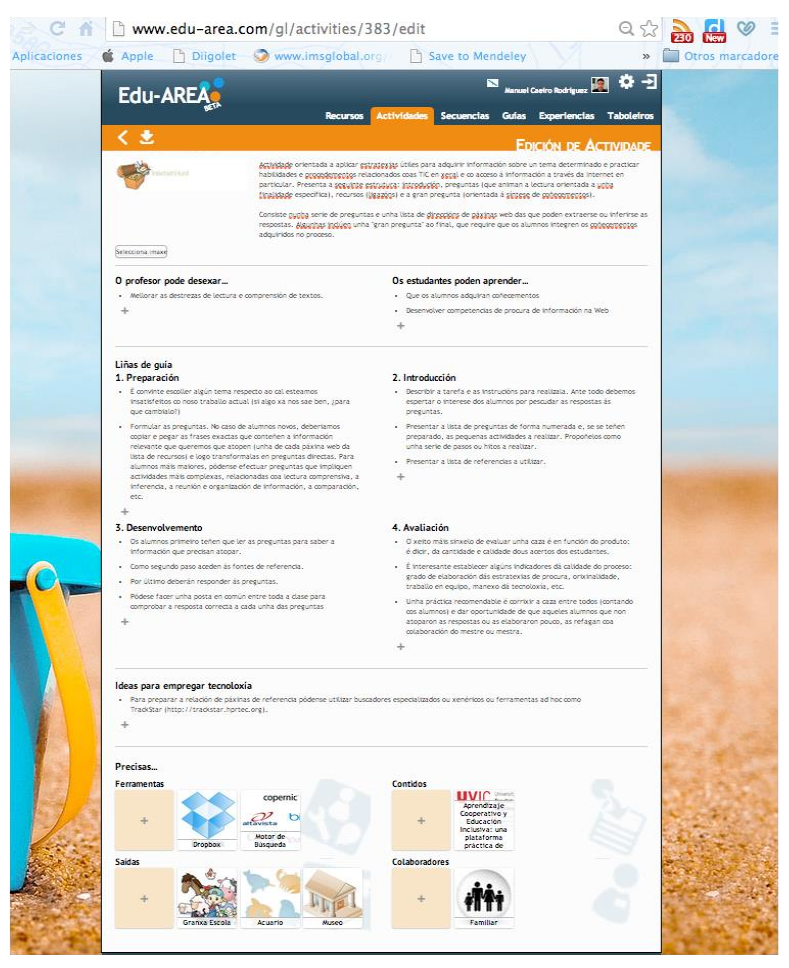

Fig. 1. Edition of an Activity in Edu-AREA

\section{Open Lesson Plans}

An OLP is conceived basically as a set of educational activities arranged by a teacher to carry out in a certain classroom. In this way, the main building block of the OLP data model is the educational activity data model. In addition, the OLP also involves some sections related to the description of the specific setting in which it will be carried out. Furthermore, from a posteriori point of view, we also consider in the OLP the information produced after the development of the lesson plan, namely: evidences and reflections. Finally, metadata and paradata information is also considered in relation to the OLP data model.

An OLP can include several educational activities. At the current state of development in Edu-AREA we just support the aggregation of activities as Activity Sequences. This arrangement has no implication because Edu-
AREA doesn't support any automatic enactment. It just indicates the order in which activities are shown. Nevertheless, in the future we consider the extension of Activity Sequences to Activity Ensembles and to introduce other options for presentation and enactment.

Related to the setting we consider two different types:

-A Technical Setting, describing the technologies (applications and devices) available at the classroom.

- An Educational Setting, describing the geographical location, dates, learners, subject, etc.

The idea of separating these issues is to facilitate the reuse of the OLP at different classrooms or schools just by replacing these settings. In Edu-AREA this information is maintained to support recommendations of resources. For example, to locate an event at specific dates near the school.

Finally, the consideration of the OLP as a living entity introduces the need to consider a new set of information: experiences. Therefore, for each activity an Experience Record is maintained. This Experience Record includes information about the state of development (e.g. "Not initiated", "Running", "Stoped", "Finished), the init and end dates, and a number of evidences and reflections. Evidences are pictures, videos or audio recordings captured during the development of the activity, or any relevant outcome. Reflections are positive or negative comments, or lessons learned that a teacher wants to provide about the general development. We consider this information can be very valuable for OLP in order to support their continuous enhancement and evolution.

\section{CONCLUSION}

In this paper we have introduced some ideas towards the specification of a data model for 
OLP. We think this kind of specification can become a key contribution in order to promote teaching innovation, mainly involving ICT, new pedagogies and OER. Currently, several dozens of applications to support authoring of educational resources are available, also related to lesson plans or similar constructs, such as courses and learning designs. Similarly, applications to support classroom operation for Android and IOS are also available. We believe that there is an increasing demand to support interoperability and reusability in this area and we want to explore and contribute to it. Nevertheless, we don't need to begin from scratch, but existing specifications can be taken and adapted.

The work presented in this paper is being performed in the context of a larger initiative: Edu-AREA. The OLP data model can play a key role in order to support the import and export of teacher resources in the platform. In addition, we are also developing a REST API in order to facilitate the development of third-party applications that can use the functionalities provided. The data model introduced in this paper is going to play a key role in the resources and messages of the API.

\section{REFERENCIAS}

[1]. Hodgins, W. (2002). IEEE 1484.12.1-2002 Learning Object Metadata standard. (E. Duval, Ed.) (pp. 1-44). IEEE, 2002.

[2]. SCORM ADL. SCORM 2004 4th Edition, $2012 . \quad$ Retrieved from http://www.adlnet.gov/scorm/

[3]. IMS GLC Learning Design Specification, 2013. Retrieved from http://www.imsglobal.org/learningdesign/in dex.html
[4]. UNESCO. 2012 Paris OER Declaration. Paris. Retrieved from http://www.unesco.org/new/fileadmin/MUL TIMEDIA/HQ/Cl/Cl/pdf/Ev ents/Paris OER Declaration_01.pdf

[5]. O'reilly, T. What is Web 2.0: Design patterns and business models for the next generation of software. Communications \& Strategies, (65),2007.

[6]. Caeiro-rodríguez, M., Pérez-rodríguez, R., García-alonso, J., Manso- vázquez, M., \& Llamas-nistal, M., "AREA : A Social Curation Platform for Open Educational Resources and Lesson Plans". In Frontiers in Education Conference, 2013 IEEE, pp. 795 - 801. Oklahoma City, OK: IEEE, 2013.

[7]. Boyle, T., "Layered learning design: Towards an integration of learning design and learning object perspectives." Computers \& Education., vol. 54, pp. 661668, 2010

doi:10.1016/j.compedu.2009.09.026

[8]. Alario-hoyos, C., Pérez-sanagustín, M., Cormier, D., \& Delgado-kloos, C. , "Proposal for a Conceptual Framework for Educators to Describe and Design MOOCs," Journal of Universal Computer Science, vol. 20, no.1, pp. 6-23, 2014.

[9]. Hernández-Leo, D., Chacón, J., Prieto, L. P., Asensio-Pérez, J. I., \& Derntl, M., "Towards an Integrated Learning Design Environment," In D. Hernández-Leo, T. Ley, R. Klamma, \& A. Harrer (Eds.), Scaling up Learning for Sustained Impact. 8th European Conference, on Technology Enhanced Learning, pp. 448-453, 2013.

[10]. Villasclaras-Fernández, E., HernándezLeo, D., Asensio-Pérez, J. I., \& Dimitriadis, Y. , "Web Collage: An implementation of support for assessment design in CSCL macro-scripts. Computers \& Education, vol. 
67, pp. 79-97, 2013. doi:10.1016/j.compedu.2013.03.002

[11]. [11] Sobreira, P., \& Tchounikine, P., "A model for flexibly editing CSCL scripts," International Journal of ComputerSupported Collaborative Learning, vol. 7, no. 4, pp. 567-592, 2012.

[12]. Persico, D., \& Pozzi, F. , "Task, Team and Time to structure online collaboration in learning environments,". World Journal on Educational Tecnology, vol. 3, no. 1, pp 115, 2011.

[13]. Laurillard, D., Charlton, P., Craft, B., Dimakopoulos, D., Ljubojevic, D., Magoulas, G., Whittlestone, K. (2011). A constructionist learning environment for teachers to model learning designs. Journal of Computer Assisted Learning, 29(1), 1530.

[14]. Derntl, M., Neumann, S., \& Oberhuemer, P., "Propelling Standards- based Sharing and Reuse in Instructional Modeling Communities: The Open Graphical
Learning Modeler (OpenGLM)," IEEE 11th International Conference on Advanced Learning Technologies, pp. 431-435, 2011.

[15]. Katsamani, M., "Making learning designs in layers: the CADMOS approach," In IADIS Multi Conference on Computer Science and Information Systems, 2011.

[16]. [16] Pérez-Sanagustín, M., \& HernándezLeo, D., "4SPPIces: Factors in the Design of Adaptive and Intelligent Systems for $\mathrm{CL}$ Scripts Blending Spaces," IEEE Learning Technology Newsletter, vol. 14, no. 1, pp. 12-15, 2012.

[17]. Emin, V., Pernin, J.-P., \& Aguirre, J. L., "ScenEdit: An Intention- Oriented Authoring Environnment to Design Learning Scenarios". In M. Wolpers, P. A. Kirschner, M. Scheffel, S. Lindstaedt, \& V. Dimitrova (Eds.), Sustaining TEL: From Innovation to Learning and Practice. 5th European Conference on Technology Enhanced Learning, EC-TEL 2010, pp. 626-631, 2010. 